\title{
Customer economics of residential photovoltaic systems: Sensitivities to changes in wholesale market design and rate structures
}

\author{
Naïm R. Darghouth*, Ryan H. Wiser, Galen Barbose \\ Ernest Orlando Lawrence Berkeley National Laboratory, 1 Cyclotron Road, MS 90R4000, \\ Berkeley CA 94720, USA \\ * Corresponding author. Tel.: +1-510-486-4570. Email address: ndarghouth@lbl.gov
}

\begin{abstract}
Abbreviations: $\mathrm{CSP}=$ concentrating solar power, $\mathrm{HN}=$ hourly netting, $\mathrm{IBP}=$ increasing-block pricing, IOU = investor-owned utility, $\mathrm{NM}=$ net metering, PG\&E = Pacific Gas \& Electric, PV $=$ photovoltaic, $\mathrm{RE}=$ renewable electricity, $\mathrm{RTP}=$ real-time pricing, $\mathrm{SCE}=$ Southern California Edison, SDG\&E = San Diego Gas \& Electric, T\&D = transmission and distribution, TOU = time of use
\end{abstract}




\section{Introduction}

The customer economics of residential solar photovoltaics (PV) rely heavily on the level of compensation for PV-generated electricity. In the United States, this compensation is often based on the customer's prevailing retail electricity rate because of net metering-by far the most common U.S. PV compensation scheme. Net metering compensates all (or a portion) of PV generation at the customer's underlying retail rate, thus rate design has a significant impact on the economics of behind-the-meter PV. When considering the private economics of residential PV, payback calculations often assume that current retail rates will remain fixed or increase (in real terms) over the PV system's lifetime. These calculations do not consider the changes in retail rates that could result from increased penetration of renewable generation technologies, both utility scale and behind the meter, as well as from changes in wholesale electricity market design and retail electricity rate structures. Future installations of residential PV systems are very dependent on the underlying retail rates, and future installation trends could vary greatly with differing wholesale electricity market designs and rate structures.

In a previous article, we found that "high renewable penetrations can drive substantial changes in residential retail rates and that these changes, together with variations in retail rate structures and PV compensation mechanisms, can interact to place substantial uncertainty on the future value of bill savings from residential PV" [1]. More specifically, all rate structures and compensation mechanisms investigated, other than a flat time-invariant rate with net metering, reduced the bill savings from PV generation-in some cases substantially.

We made a number of assumptions regarding the retail rate structures in our previous paper [1]. The electricity rates investigated in the first article were based on wholesale prices that 
enable peaker plants to recover their costs in the hours when capacity is constrained (through the energy-only market design), and fixed costs were recovered through volumetric charges, as they are in many utility rates today. In addition, the flat rate was implemented in this analysis without increasing-block pricing (IBP), in contrast to today's rate design in California's three largest investor-owned utilities (IOUs). In this article, we consider a set of particularly timely assumptions that could affect the customer economics of behind-the-meter PV:

(a) Retail rates based on an electricity market with a price cap of $\$ 1,000 / \mathrm{MWh}$ and recovering capacity costs to ensure the same level of resource adequacy by adding a volumetric charge to each kilowatt-hour of electricity sold. Although some wholesale electricity markets employ an energy-only model (e.g., the Electric Reliability Council of Texas), many others implement a wholesale price cap with capacity payments to generators to ensure sufficient capacity and reliability. This could affect retail electricity rates, particularly if capacity payments are recovered through a volumetric adder to rates.

(b) Retail rates that recover fixed costs through a two-part tariff consisting of a volumetric energy charge and a fixed customer charge. Arguing that PV customers avoid paying their share of fixed costs owing to net metering, some U.S. utilities are looking to implement a two-part tariff, in which all customers are subject to a fixed monthly fee in addition to a (lower) volumetric energy charge. Because PV generation could not displace any of the fixed charge, the bill savings from PV would decrease, impacting the customer economics of net-metered PV.

(c) A tiered flat rate with IBP. The rationale for tiered rates is to encourage lower total electricity consumption and to provide a baseline level of electricity at a low price (for lower-income customers, for example). Tiering, however, does not account for the timing of consumption, and 
there is no clear theoretical method for designing tiered rates. Still, the flat rate with IBP is the default rate for many utilities, including the IOUs in California, thus we design a tiered flat rate to analyze the impacts of tiering on the bill savings from PV.

A number of previous studies cover the links between renewable energy, wholesale electricity markets, and retail rate design. Some researchers have studied the wholesale price impacts of renewable energy. For example, Sáenz de Miera et al. [2] and Sensfuß et al. [3] consider the short-run wholesale price impacts of increased renewable energy using modeling frameworks that account for the "merit-order" effect. Lamont [4] and Mills and Wiser [5] use models that simultaneously consider economic investment and dispatch to generate wholesale prices representing markets in long-run equilibrium for increased-renewable scenarios. Other researchers have examined the links between current retail rates and customer economics of behind-the-meter PV. For example, Darghouth et al. [6] quantify the value of bill savings for netmetered residential PV using current retail electricity rates. Borenstein [7] explores the impact on bill savings of mandatory time-of-use (TOU) rates for net-metered residential PV customers, and he shows that PV customers can often benefit from time-varying retail rates over flat rates [8]. Mills et al. [9] investigate retail rate structure impacts on the value of bill savings for commercial California customers, focusing in part on how much PV can reduce customer demand charges. A follow-on to this study examines the impacts of changes to rate design and net metering rules on future distributed PV deployment resulting from changing customer economics from PV [10].

However, prior to this article series, the literature has not considered how retail rate design and compensation mechanisms interact with changes in future wholesale price profiles. ${ }^{1}$ This

\footnotetext{
${ }^{1}$ For a comprehensive review of the relevant literature on the interactions between retail electricity rate design and the customer economics of PV, refer to Darghouth [11].
} 
article is designed to fill that gap. Our previous article [1] examined these issues using a baseline set of assumptions, which included an energy-only wholesale market and rates that recovered costs entirely through volumetric charges. This article examines essential variations to wholesale market and retail rate design, which are particularly relevant given current electricity-policy debates in the United States.

\section{Methods $^{2}$}

Two scenarios are considered throughout the analysis in this article and are summarized in Table 1: (1) a reference scenario in which the renewable energy capacity is based on 2011 levels and remains constant through 2030, and (2) a 33\% renewable electricity (RE) mix scenario in which a third of the electricity supply is from a mix of renewable energy technologies. The price of natural gas is assumed to be $\$ 6.40 / \mathrm{MMbtu}$, as per the U.S. Energy Information Administration's reference scenario [12]; there are 3.6 GW of pumped hydro storage; and concentrating solar power (CSP) has a 6-hour storage capacity.

To investigate potential impacts of wholesale market design and various rate structures on the value of bill savings for residential PV customers, we use the following methodology:

1) Model the impacts of a wholesale electricity market design with price caps and two rate structures (one with IBP and one with two-part tariffs) on hourly wholesale market prices

2) Design residential retail rates for each scenario, assuming full cost recovery of variable and fixed costs

3) Using net metering (and, in some cases, an alternate form of compensation) to remunerate behind-the-meter residential PV generation, for each retail rate type and

\footnotetext{
${ }^{2}$ The data and methods are similar to those in our previous article [1].
} 
scenario considered, compute the bill savings from PV for residential customers by calculating their annual bill with and without PV generation.

The production-cost and capacity-expansion model used to develop wholesale electricity prices in this analysis is from Mills and Wiser [5]. This model assumes an energy-only market, where prices are permitted to reach very high levels in some hours to recover the fixed costs of peaker plants. The baseline analysis in our previous article [1] used this model to develop hourly wholesale electricity prices. In this article, one of the scenarios investigated is an alternative market design with lower price caps, based on the energy-only model results but with prices truncated at times when prices rise above the cap.

We use growth-adjusted load data based on California's gross retail load in 2010 [13] as input to the production-cost and capacity-expansion model. The model outputs wholesale prices assuming a generation mix of plants that are within their technical lifetime in 2030 (see Mills and Wiser, 2013) and new plants that, together, meet load and reserve requirements, given the renewable electricity generation profiles. Darghouth et al. [14] provide renewable generation site-selection details.

Our analysis is based on electricity market characteristics that are, in part, loosely based on California's, but is not intended to be a forecast of California's electricity market, nor are our conclusions intended to have implications specific only to the California market. We chose to base some of our assumptions on California's electricity market in 2030 as (a) California has the highest levels of installed solar capacity of any state in the US, (b) its renewable energy capacity continues to grow, with aggressive renewable portfolio standards, making it a good candidate for 
a high renewable scenario, and (c) the availability of electricity market-related and customer data enables such analysis.

Standard rate-design principles are used to develop the retail electricity rates [1]. Rates are set to recover the utility's fixed costs and variable costs plus a fair rate of return. The flat rate, without tiering, is the average cost of generating, transmitting, and delivering electricity to residential customers. The time-of-use (TOU) rate charges higher prices during times of peak wholesale prices and is systematically computed using a k-means clustering algorithm. Real-time pricing (RTP) charges the hourly wholesale price in addition to a volumetric charge. These three rates (flat, TOU, and RTP) are developed for the alternative wholesale market design and the two-part tariff. The detailed framework and methodology for developing each of the retail rates can be found in Darghouth [11].

The two compensation mechanisms considered in this article are net metering and hourly netting. Net metering effectively compensates all PV generation at the underlying retail rate. For time-varying rates, net metering compensates hourly PV generation at the rate applicable in each hour. Under net metering, bill savings are not dependent on the customer's load profile. With hourly netting, PV generation can displace electricity consumption within the hour (effectively compensating generation that offsets consumption at the retail rate), but any excess electricity is compensated at the wholesale price. Because the rate of compensation depends on consumption in any hour, bill savings depend on the customer's load profile (see [1]).

Annual bills are calculated using the retail rates developed for a sample of 226 customers of the three IOUs in California, for which we have hourly consumption profiles for a 1-year 
period. ${ }^{3}$ We use modeled contemporaneous PV generation, matched to each customer's location, to calculate annual bills with PV. In most of the analyses presented, each customer's PV system size is designed to meet $75 \%$ of the customer's annual consumption (we call this a $75 \%$ PV-toload ratio). We also present results for $25 \%$ and $50 \%$ PV-to-load ratios for a subset of the results.

The value of bill savings is expressed as dollar savings per kilowatt-hour of PV generation. It is calculated by taking the difference between the customer's annual bill with and without PV and dividing by the customer's annual PV generation.

To summarize, the scenarios include two wholesale market design options (with and without a wholesale market price cap), two renewable penetration scenarios (reference and 33\% renewable penetration), three rate design options (flat, TOU, and RTP rates), and two compensation mechanisms (net metering and hourly netting).

\subsection{Lower wholesale price cap}

There are a variety of wholesale market designs that enable all market participants to recover their fixed and variable costs. One market solution is the energy-only market design, where prices in most hours are set by the highest bidder, as per the merit order curve. In the hours where capacity is constrained, however, prices are allowed to spike as high as the value of lost load, which allows for peaker plants to recover their fixed costs through wholesale prices. This was the energy market design used for the analysis in our previous article [1]. However, a number of markets implement a wholesale price cap which is much lower than the value of lost

\footnotetext{
${ }^{3}$ Customers in the sample were not PV system owners. They consumed a median of $8,568 \mathrm{kWh} / \mathrm{year}$ and a mean of 9,431 kWh/year. This is higher than household mean values for all customers in PG\&E (6,734 kWh/year), SCE (6,783), and San Diego Gas \& Electric (SDG\&E, 5,943) [15] but lower than the gross electricity consumption for the subset of customers with net-metered PV: 13,776 (PG\&E) and 17,208 (SCE) kWh/year [16].
} 
load, and side payments are made to generators to ensure sufficient capacity to meet load. The impact of the latter market design (lower price cap with a separate capacity market) on electricity bill savings from PV under net metering is investigated in this article. More detailed reviews of the energy-only model and capacity markets can be found in Stoft [17], CPUC [18], Wen et al. [19], Oren [20], Joskow [21], Newell et al. [22], and Darghouth et al. [1].

Electricity rates that are designed efficiently, to send the proper price signals to customers, would recover the generation capacity costs during peak times, as it is only in the peak hours that individuals contribute to increased generation capacity costs. For the TOU and RTP rates, the capacity costs would be recovered via a volumetric adder only in the peak period or hours. These rates would be equivalent to those under an energy-only market, because all price spikes in the modeled wholesale market occur during the peak TOU period. As the flat rate is time-invariant, the capacity costs would recovered via a volumetric adder spread over all hours, and hence result in the same rate level whether under an energy-only market or a market with a price cap with side capacity payments. Hence, when rates are designed more efficiently, we would not expect any difference in the bill savings from PV resulting from the wholesale market characteristic related to price caps.

However, a number of utilities do not design their TOU rates in this way, instead choosing to recover at least a portion of their generation capacity costs via a volumetric adder spread over all hours. For example, the Ontario Energy Board set their TOU rates in this way until recently [23]. Some utilities recover these costs over both the mid-peak and peak periods, which span over a large portion of the day. Were TOU and RTP rates to always be calculated efficiently, then our results would be the same with or without a price cap, given that generation capacity costs are to be recovered in peak periods in both cases. However, recognizing that some time- 
varying rates do not send customers efficient price signals, we also compute retail rates based on an electricity market with lower price caps and capacity costs recovered evenly over all electricity consumption via a volumetric adder. This effectively changes the time-varying rates so that, instead of being based on wholesale prices that can reach $\$ 10,000 / \mathrm{MWh}$, we use the same output from the production-cost and capacity-expansion model (described in the introduction to Section 2$)$ but limit the wholesale electricity price $\left(p_{h, c a p}\right)$ such that:

$$
p_{h, \text { cap }}=\left\{\begin{array}{c}
p_{h} \text { if } p_{h} \leq 1,000 \\
1,000 \text { if } p_{h}>1,000
\end{array}\right.
$$

For the generators selling power during peak hours when prices are higher than $\$ 1,000 / \mathrm{MWh}$ under the higher price cap, the lost income is recovered by a volumetric capacity cost adder $\left(R_{\text {cap }}\right)$. This ensures that plants depending on these high payments to recover their capital costs provide sufficient capacity in those peak-demand hours. The revenue requirement with a lower price cap and a capacity-cost adder is the same as with a higher wholesale price cap. Thus, the capacity-cost adder $\left(R_{\text {cap }}\right)$ is defined such that the total cost of purchasing wholesale electricity under the higher price cap is equal to the sum of the costs of purchasing wholesale electricity under the lower price cap and the total revenue from the capacity-cost adder. In addition, the flat rate, which is based on a load-weighted average wholesale price, does not change with the lower price cap plus the capacity-cost adder, because the total revenue is equal to the flat rate under the higher price cap.

We recalculate all rates (with net metering and hourly netting) using the capped wholesale price time series for the reference scenario and the $33 \% \mathrm{RE}$ mix scenario, where all rates are 


\subsection{Two-part tariff}

In the analysis presented in our previous article [1], we only considered electricity rates with volumetric charges (i.e., a customer with zero net electricity consumption would have a zero electricity bill). In this article, one of the rates we consider has a fixed customer charge. Several utilities have considered or are considering charging PV customers a monthly fee or standby charge to cover fixed costs related to grid connection or increasing the monthly fixed charge (while decreasing the volumetric charge) to better reflect their cost structures. In this way, a customer with a zero net annual consumption would still have a non-zero bill equal to the fixed charge. The current analysis includes a version of the two-part tariff, a lower volumetric rate and a fixed customer charge, under the reference scenario and the $33 \%$ RE mix scenario.

In particular, we consider a two-part tariff with a uniform fixed fee, which recovers all of the utilities' fixed costs through a customer charge that does not vary with customers' annual consumption in addition to transmission and distribution $(\mathrm{T} \& \mathrm{D})$ related costs. ${ }^{4} \mathrm{~T} \& \mathrm{D}$ capacity costs are recovered in the fixed customer charge as these tend to scale with the number of customers (beyond the month-to-month time scale) and, furthermore, most utilities have chosen not to differentiate fixed customer charges based on the size of the customer's electrical connection. With net metering and hourly netting, customers cannot displace any part of the customer charge. The variable portion of the rate-which can be displaced by PV generation-

\footnotetext{
${ }^{4}$ The fixed charge includes recovery of costs related to renewable purchase power agreements, T\&D infrastructure capacity costs, miscellaneous charges such as a public purpose program charge, and the fixed costs of operations and maintenance related to utility-owned generation (hydro power plants, pumped storage, and nuclear plants).
} 
only recovers the costs of electricity purchases on the wholesale market. Since an energy-only market design is assumed in this study, the fixed costs of peaker plants required to ensure resource adequacy (i.e., "generation capacity costs") are reflected in wholesale electricity prices, and hence generation capacity costs are recovered through the variable portion of the two-part tariff.

With the real-time rate, the customer's energy charge is assumed equal to the wholesale price each hour, and the fixed charge is determined by the residual revenue required to recover total utility costs. ${ }^{5}$ The real-time rate is likely the most efficient rate, because it sets the volumetric cost to the marginal cost of generating electricity and the fixed cost to recover all revenue shortfalls. However, this rate likely recovers too many of the fixed costs from PV customers. Thus it might be a lower bound to what a utility actually may implement, because PV can displace some fixed costs, such as offsetting T\&D upgrades, and this rate does not consider potential benefits of behind-the-meter PV such as reduced line losses and environmental benefits. See, for example, Ràbago et al. [24] for a review of the potential benefits of PV not accounted for in this analysis.

\subsection{Tiered rates}

We create a tiered flat rate for both the reference and the $33 \%$ RE mix scenario (i.e., a rate with IBP but without any time-differentiated pricing). The tiered rate is based on the flat rate, where all costs are recovered through a single rate. Because there is little theoretical rationale for the specific characteristics of any tiered flat rate, a number of assumptions must be made

\footnotetext{
${ }^{5}$ This is not quite equivalent to the RTP rate presented in Darghouth et al. [1] with volumetric charges only, because none of the remaining charges are recovered with a volumetric charge. Thus comparisons between the RTP rate in Darghouth et al. [1] and with a customer charge are not made directly in figures or the text.
} 
regarding the size of the steps (in kilowatt-hours) and the increase in rate with each step. In this study, the tiered flat rate has three tiers (including a baseline) and can be described fully in the following three equations to produce a unique solution:

$$
\begin{gathered}
t_{\text {baseline }} \cdot R_{\text {gen,baseline }}+t_{2} \cdot R_{\text {gen }, 2}+t_{3} \cdot R_{\text {gen }, 3}=R_{\text {gen }, \text { flat }} \\
\left(R_{\text {gen,baseline }}+R_{\text {adder }}\right) \cdot\left(1+s_{2}\right)=R_{\text {gen }, 2}+R_{\text {adder }} \\
\left(R_{\text {gen }, 2}+R_{\text {adder }}\right) \cdot\left(1+s_{3}\right)=R_{\text {gen }, 3}+R_{\text {adder }}
\end{gathered}
$$

where $R_{\text {gen,baseline }}, R_{g e n, 2}$, and $R_{g e n, 3}$ are the components for the baseline, second, and third tier, respectively, that recover the total cost of wholesale purchases; $R_{\text {gen,flat }}$ is the component of the non-tiered flat rate that recover the total cost of wholesale purchases; $R_{\text {adder }}$ is the volumetric adder that recovers all other costs (including fixed costs); $t_{\text {baseline }}, t_{2}$, and $t_{3}$ are the percentages of net load attributed to the baseline, second, and third tier, respectively; and $s_{2}$ and $s_{3}$ are the percent increases in rate from baseline to tier 2 and from tier 2 to tier 3 , respectively. The values for each of these constants are summarized in Table 2.

These values are loosely based on the current tier structure for Pacific Gas \& Electric (PG\&E) and Southern California Edison (SCE). The baseline amount in California is designed to cover $50 \%-60 \%$ of average load (hence a value of $55 \%$ was used). Tier 2 corresponds to consumption from $100 \%$ up to $150 \%$ of the baseline level, and tier 3 corresponds to all consumption over that level. The step increase in total rate from baseline to tier 2 is $50 \%$, and the 
step increase from tier 2 to tier 3 is $100 \%$. Baseline regions and seasonal levels are equivalent to those of the three major IOUs, as of January $2013 .^{6}$

\section{Results}

In this section, we will compare the bill savings for each combination of the three rate designs, three PV-to-load ratios, two renewable penetration scenarios and two compensation mechanisms under an energy-only market, a wholesale market with price cap and side capacity payments, and with and without fixed customer charges ${ }^{7}$. Additionally, we will compare bill savings with net metering under IBP to bill savings under a flat rate in the reference scenario. Positive values in the figures indicate that bill savings from PV for the customer would be higher than in the reference scenario, and negative values indicate lower bill savings from PV, as compared with the baseline scenario specified for each figure. All modeled retail rates are summarized in Table 4; scenarios in the table have been labeled A-H and are explicitly labeled in the text.

\subsection{Volumetric rate under an energy-only market (scenarios $A \& C$ )}

When retail rates are modeled such that all utility costs are recovered via a volumetric charge (i.e., no fixed customer charges), under the reference scenario $(A)$, time-varying rates increase bill savings with net metering when compared to the flat rate. This is because wholesale

\footnotetext{
${ }^{6}$ The three IOUs in California (SCE, PG\&E, and SDG\&E) have developed baseline regions based on climate zones, and they assign a baseline level of electricity consumption appropriate for each climate zone. Baseline regions with higher temperatures in the summer are allotted a higher baseline level than more temperate coastal regions, for example.

${ }^{7}$ Some scenario or rate combinations are not applicable or not covered in this study. The RTP rate, as defined in this study, always has a fixed charge which is not calculated in the same way as the fixed charge for flat and TOU rates (i.e. the fixed charge for RTP rate is designed to recover all costs not recovered via the variable portion of the rate whereas the fixed charge for the flat and TOU rates is designed to recover fixed costs and T\&D capacity costs). The only IBP analysis is under the flat rate in the reference scenario.
} 
electricity prices are generally higher than average during times when PV generates electricity (i.e., PV output is positively correlated to summer peak load), and PV generation therefore benefits from time-differentiated compensation. Relative to the reference case, the bill savings increase under the 33\% RE mix scenario $(C)$ with the flat rate and net metering (due to the increased costs of renewables) but decrease for time-varying rates (because wholesale prices during times of PV generation erode with increasing PV penetration).

For both the reference $(A)$ and the $33 \%$ RE mix scenario $(C)$, hourly netting decreases bill savings by $27 \%-47 \%$ relative to the same rate with net metering. Over most hours in which hourly excess PV is exported to the grid, wholesale prices are lower than retail rates (whether flat, TOU, or RTP), yielding a sizable decrease in the value of bill savings, particularly when hourly exports are a large portion of total PV generation.

These results can be observed in columns 1 and 3 (energy-only market) of Figure 1 and are discussed comprehensively in Darghouth [11]. Figure 1 shows the value of bill savings from PV under each of the rate options for the reference scenario $(A \& B)$ and the $33 \%$ RE mix scenario $(C \& D)$, relative to the flat rate with net metering in the reference scenario; these results are for the energy-only market and the lower price cap with the capacity-cost adder, assuming a 75\% PV-to-load ratio. ${ }^{8}$

\footnotetext{
${ }^{8}$ All figures show a percentage increase or decrease from a baseline, because this study is mostly interested in the directional change and relative magnitudes of bill savings rather than the exact numbers, which depend more on the retail rate levels developed from the underlying assumptions. However, the absolute bill savings for all points in the figures can easily be computed, given that the beginning reference point (bill savings for the flat rate with net metering in Figure 1) is equal to $\$ 0.179 / \mathrm{kWh}$. The absolute bill savings levels for all scenarios are also found in the appendices of Darghouth [11].
} 
3.2 Lower wholesale electricity price cap and volumetric capacity charge (scenarios $B \& D$ )

With a lower wholesale electricity price cap, price spikes are limited to $\$ 1,000 / \mathrm{MWh}$ (versus $\$ 10,000 / \mathrm{MWh}$ with the energy-only market), although the number of spikes on any given day does not change. The rates are designed such that in both cases, with and without an energy-only market, the same revenue levels are collected to ensure sufficient cost recovery to maintain the same level of resource adequacy. With a lower cap, this is done by way of a parallel capacity market. As explained in Section 2.1, the costs of ensuring sufficient capacity are recovered through a flat volumetric charge, which is added to the retail rate for residential customers. The resulting capacity-cost adder ranges from $\$ 0.019 / \mathrm{kWh}$ to $\$ 0.020 / \mathrm{kWh}$, depending on the scenario and the PV compensation mechanism assumed.

The flat rate in the energy-only market is the same as that with the low price cap and parallel capacity market. Therefore, the values of bill savings from PV with net metering are equal in both reference scenarios $(\$ 0.179 / \mathrm{kWh}-A \& B)$, as shown by the two leftmost solid diamonds in Figure 1.

Results for the energy-only market (with a $\$ 10,000 / \mathrm{MWh}$ price cap) are discussed in detail in our previous article [1] and are presented here to enable comparison with results for the lower price cap. For the reference scenario under the low price cap $(B)$, the bill savings from PV for customers under the TOU rate with net metering are $4.6 \%$ higher than under the flat rate with net metering. As with the energy-only market, this increase in bill savings is due to the coincidence between the higher-priced TOU periods and PV generation; the peak TOU period in the highpriced season is 1 to 7 pm during business days. However, this increase in value of bill savings, relative to the flat rate, is lower than for the energy-only market (12.7\%); although the peak 
period in the high-priced season is similar to the peak period in the energy-only model, the peak rate is about half the level $(\$ 0.283 / \mathrm{kWh}$ vs. $\$ 0.493 / \mathrm{kWh}$ for the low-price-cap and energy-only model, respectively). The capacity-cost adder is added to all hours, raising the rate in all other hours by $\$ 0.02 / \mathrm{kWh}$, which increases the value of bill savings with the low price cap. For the RTP rate with net metering, the value of bill savings from PV with a lower price cap is similar to that with the energy-only model, even though the rates during the peak hours are lower due to the low price cap. Again, the effect of the $\$ 0.02 / \mathrm{kWh}$ capacity-cost adder in all hours counters the decrease in the peak-period rate.

With hourly netting under the reference scenario $(B)$, there is a considerable decrease in the value of bill savings for all rates with the low price cap and capacity-cost adder. For both the energy-only market and the lower price cap (scenarios $A \& B$ ), the decrease in value with hourly netting is due to low wholesale price compensation levels for hourly net excess PV generation. Because the average wholesale price of net excess PV generation is significantly lower than the retail rate, the average value of bill savings is lower for hourly netting. As seen in Figure 1, with hourly netting, the value is even lower than in the energy-only model owing to the lower price cap and the reduction in average hourly wholesale prices of the customers' hourly net excess PV generation.

For the 33\% RE mix scenario $(D)$, the value of bill savings with net metering is again the same for the flat rate regardless of the wholesale price cap level. In contrast, both time-varying rates with net metering lead to higher bill savings from PV in the low-price-cap design compared with the energy-only design. In addition, the dramatic value reduction observed with increasing PV penetration for the energy-only model in the $33 \%$ RE mix scenario ( $D$ - shown in Darghouth et al. [1]) is not observed with the lower price cap (Figure 2), even though peak prices still shift 
to later in the day. This counterintuitive result is due to the volumetric adder being a higher proportion of the total retail rate, with the lower price cap. The portion of the rate that recovers the wholesale market purchases, $R_{g e n}$, does decrease significantly (by $48 \%$ ) owing to the shifting peak prices. However, $R_{\text {gen }}$ represents less than $30 \%$ of the total rate, and the decrease in $R_{\text {gen }}$ is countered by the increase in $R_{\text {adder }}$ because of increased RE purchases, resulting in a similar rate under the reference $(B)$ and $33 \%$ RE mix $(D)$ scenarios. This explains why the TOU and RTP rate only erode by $1 \%$ and $2 \%$, respectively, under the $33 \%$ RE mix scenario $(D)$ compared with the reference scenario $(B)$.

The value of bill savings from PV under hourly netting in the $33 \%$ RE mix scenario $(D)$ is lower than in the reference scenario for $50 \%$ and $75 \%$ PV-to-load ratios (Figure 2). As expected, as PV-to-load ratios increase, the values of bill savings decrease with hourly netting, because a greater percentage of PV generation is hourly excess and thus is compensated at the low wholesale prices. At $50 \%$ and $75 \%$ PV-to-load ratios, the only rate in the $33 \%$ RE mix scenario (D) that leads to higher bill savings is the flat rate with net metering, compared with the reference scenario.

\subsection{Two-part tariffs (scenarios $E, F, G, \& H$ )}

In this section, we consider a potential alternative rate structure to those considered in our previous article [1]: the two-part tariff. As explained in Section 2.2, two-part tariffs include a customer charge (that does not vary with electricity load and by which utilities' fixed costs are recovered) and a volumetric charge (by which utilities' variable costs are recovered). Customer charges are fixed and hence cannot be displaced by PV generation with net metering, which affects the value of bill savings from PV significantly. 

charges. The erosion in bill savings is shown in Figure 3 for the reference scenario $(E)$; under net metering, the bill savings decrease by $52 \%-58 \%$, resulting from a decrease in the volumetric portion of the rate. Under hourly netting the bill savings decrease by 33\%-36\%. The decrease under hourly netting is less significant than under net metering, because a smaller proportion of PV generation is compensated at the full retail rate than under net metering. There are no large variations in the decrease in bill savings from PV from one rate option to the next, because each of the rates considered is affected similarly; utilities recover the same amount for fixed costs via a customer charge for both time-invariant rates (e.g., flat rate) and time-varying rates (e.g., TOU rate).

Figure 4 shows PV bill-savings results for the two-part tariff structure in the reference $(E)$ and $33 \%$ RE mix scenarios $(F)$, relative to the reference scenario with flat rate and net metering. The TOU rate with net metering provides the greatest value in the reference scenario $(E)$ owing to the good coincidence between the TOU's peak periods and the hours when PV produces the most electricity, which compensates PV generation at the higher rates. The bill savings from PV are only slightly lower with hourly netting, because the average wholesale price of customers' exported electricity is only slightly less than the average TOU rate. The significant decline in value observed with volumetric rates was due to the wholesale price being much lower than the retail rate. Because there is no fixed-cost-related volumetric adder with the two-part tariff, the erosion in value resulting from using hourly netting instead of net metering is much less 
significant. With the RTP rate, ${ }^{9}$ the value is almost as high as the TOU rate, $28 \%$ higher than the flat rate with net metering. ${ }^{10}$ The lowest-value rate for the reference scenario is the flat rate with net metering. The flat rate with hourly netting leads to a higher value, because the average wholesale price during times of hourly excess generation is higher than the flat rate.

Under the $33 \%$ RE mix scenario $(F)$, all rates except for the flat rate with net metering reduce bill savings compared with the flat rate with net metering under the reference scenario (E - see Figure 4). The other rates erode bill savings because the scenario's high PV penetration reduces wholesale prices during times when PV generates. RTP is affected the most. Averaging over the TOU periods benefits PV's TOU value slightly relative to RTP. Customers with hourly netting and the flat or TOU rates would receive a lower value of bill savings than those with net metering owing to the portion of generation compensated at the low wholesale price instead of the retail rate. Hourly netting leads to a sharper decline in value, relative to net metering, for the flat rate than for the TOU rate. This is because the TOU rate is already low during hours of net excess PV generation. Since the price difference for this net excess PV generation is greater for the flat rate than for the TOU rate, the decrease in value is greater for the flat rate than the TOU rate under hourly netting. Customers with the RTP rate receive among the lowest values from PV bill savings. The RTP rate is equal to the hourly wholesale electricity price, which is the most negatively correlated to the levels of PV generation.

\footnotetext{
${ }^{9}$ As explained in Section 2.2, RTP is defined in this case as the wholesale price each hour plus a customer charge without a volumetric adder to recover variable costs other than wholesale electricity purchases.

${ }^{10}$ It may seem surprising that the value of bill savings is so much higher for RTP than for the flat rate, because the values were much more similar in the reference case with volumetric charges. This is mainly because the total residential revenue from the volumetric portion of the RTP rate (assuming all customers are on RTP rates) happens to be greater than the total revenue from the volumetric portion of the flat rate (assuming all customers are on the flat rate). This is due to the way the RTP rate is defined with these assumptions; the volumetric portion of the RTP rate is always equal to the wholesale price and does not depend on the utilities' fixed/variable cost recovery (as do all other rates considered here).
} 


\subsection{Increasing-block pricing (scenario $I$ )}

Some utilities, including California IOUs, offer IBP or tiered flat rates. With tiering, volumetric charges increase with each subsequent usage tier, and utilities typically have 2-5 tiers. We designed a tiered rate for the flat rate in the reference scenario to analyze the impacts of tiering on the value of bill savings. ${ }^{11}$ Section 2.3 describes the tiered-rate design methodology used in this analysis. Table 3 shows the tiered rates for the reference scenario.

We computed utility bills for the customer sample using this rate option with and without PV for three PV system sizes (25\%, 50\%, and 75\% PV-to-load ratio) to calculate the value of bill savings for each customer. Similar to the results in Darghouth et al. [6], customers with the highest consumption levels who faced high marginal costs in the third tier had the highest level of bill savings from PV (a 102\% increase over the non-tiered flat rate), and those with the lowest consumption levels had the lowest bill savings from PV (about 33\% lower than the non-tiered flat rate), shown in Figure 5.

The value of bill savings from PV decreases with increasing PV-to-load ratios, particularly for customers in the upper tiers. As PV generation increases, net consumption enters the lower tiers, and hence the marginal value of PV generation is at a lower-tiered rate. This results in lower average customer value from PV generation.

These results depend on the assumptions used in the design of the tiered rate. The steeper the increasing-block prices, the greater the differences between the lowest and highest tiers and the non-tiered flat rate. However, these results indicate that the variability of impact on PV bill-

\footnotetext{
${ }^{11}$ This analysis uses the reference scenario for 2030 to design the tiered flat rate. For a more detailed analysis of the impact of actual tiered rates available in California (as of 2009) on the value of bill savings from PV, see Darghouth et al. (2011).
} 
savings value due to tiered rates can be greater than the variability associated with other rate options and compensation mechanisms, depending on the design of the price tiers.

The results presented thus far have been summarized in Table 5.

\section{Discussion}

Many U.S. organized wholesale electricity markets currently consist of an energy market with price caps and a parallel capacity market that ensures resource adequacy. Under this type of market design, wholesale electricity prices are less volatile than under an energy-only market design; however, the capacity payments create an additional cost that must be recovered through retail rates. In this analysis, we recover these via a flat volumetric adder for retail residential customers, as do most U.S. utilities today. The differences with the energy-only market can affect retail rates and the value of bill savings for behind-the-meter PV in several important ways. Although there is no change in the value of bill savings under flat retail rates with net metering, time-varying rates reduce value during periods when the wholesale price cap is reached and increase value during all other periods, due to the additional volumetric capacity adder. $^{12}$ This results in only a small increase in the value of bill savings for customers with the time-varying rates and net metering under the reference scenario, because PV generates in hours with scarcity prices that would be reduced due to the price cap (TOU and RTP with net metering lead to savings that are only $2 \%$ and $5 \%$ higher than the flat rate with net metering, respectively). Conversely, with higher PV penetrations, the value of bill savings under time-varying rates increases because the price spikes in these scenarios do not occur when PV generates (i.e. the

\footnotetext{
${ }^{12}$ If the TOU and RTP rates are less "peaky," because of policy decisions on how to recover capacity costs through rates for example, then bill savings from PV will be less affected by PV output correlation with periods of scarcity. This is particularly important for wholesale market scenarios with low PV penetrations, because there is a higher level of correlation between PV generation and periods of scarcity than for higher-PV-penetration scenarios.
} 
volumetric capacity adder increases off-peak rates relative to the off-peak rates without the adder). Thus, the reduced energy costs during those hours do not affect PV compensation, while the additional volumetric charge to recover capacity-market costs increases retail rates during hours when PV generation occurs (TOU and RTP with net metering lead to savings that are 7\% and $18 \%$ higher than with the energy-only market, respectively). In short, a market with price caps and a parallel capacity market reduces the erosion in the value of net-metered TOU and RTP bill savings relative to the flat rate that occurs in an energy-only market at high solar penetration.

Our previous article [1] considered three potential residential retail rate structures (a flat rate, a TOU rate, and an RTP rate), and in all cases fixed costs were recovered through volumetric charges. Some jurisdictions, however, are considering relying more heavily on customer charges for fixed-cost recovery. Hence, in this article we considered, as a lower bound to $\mathrm{PV}$ value, a case in which all fixed costs are recovered through a fixed customer charge rather than a volumetric adder (resulting in a customer charge of $\$ 59 /$ month). The most salient result is the substantial decline, over 50\% using the assumptions in this analysis, in the value of bill savings for the flat and TOU rates with net metering, relative to that of the full volumetric rate. The policy implications are also significant; depending on how the rate is designed, moving away from volumetric-only rates to two-part tariffs could significantly affect the customer economics of residential PV and the behind-the-meter PV market. To retain demand for PV at a similar level, such a reduction in value from bill savings would need to be countered by a feed-in tariff, an upfront subsidy, or another compensation mechanism to increase the PV system's value to the customer. 
Using the specified assumptions, we found that the flat and TOU rates with the two-part tariff provide 52\%-58\% lower value compared with similar rates with volumetric-only charges, assuming net metering. Specifically, this study assumes that all utility fixed costs are recovered through the fixed customer charge, resulting in a relatively high monthly charge of \$59 for 2030 rates (in 2012 US\$). Fixed charges for California investor-owned utilities are currently limited to \$10/month, as per legislation (AB 327), and some California municipal utilities are ramping up their fixed charge to $\$ 20 /$ month in the coming years. We chose to model this higher fixed charge, however, as an upper bound to what utilities may consider in the future. Clearly, a \$20 customer charge, with a volumetric adder to recover the remaining utility fixed costs (scenarios $G \& H$ ), would result in a substantially less erosion in bill savings (17\%-19\% reduction) compared with similar rates with volumetric-only charges, assuming net metering. As customer charges increase, value of bill savings from PV continue to decrease linearly. With a $\$ 20$ customer charge, all of the relationships in Figure 4 are maintained, though the effects of the fixed charge are less pronounced.

At low PV penetrations, time-varying rates provide the highest value of bill savings from PV, as exemplified in the reference-scenario results (the TOU and RTP rates lead to savings $30 \%$ and $28 \%$ higher than the flat rate, respectively). As with the volumetric-only rates, the portion of the rates derived from wholesale energy purchases is higher during times of PV generation, and hence PV generation benefits from above-average rates. With high PV penetrations, peak prices shift to later in the day when PV stops generating. Thus prices when PV generates are low, leading to lower value of bill savings from PV, as seen in the 33\% RE mix scenario results (the TOU and RTP rates lead to savings $24 \%$ and $31 \%$ lower than the flat rate, respectively). Without the volumetric adder, the differences between the two-part tariff time-varying rates and the 
average wholesale prices are smaller, and hence, for time-varying rates, the impact of moving from net metering to hourly netting is less significant than with volumetric-only rates.

Our results assume fixed customer profiles to calculate bill savings from PV under each wholesale market model and retail rate scenario. However, different consumer load profiles could have an impact on the calculated bill savings from PV, depending on the load profile or scenario. In most cases, for customers under full net metering, their bill savings are independent from the customer's load level or the coincidence of PV generation and consumption, when their PV generation is less than their annual load levels. ${ }^{13}$ As such, the bill savings per unit energy generated from PV does not depend on the shape of the customer's load profile. In contrast, for customers under partial net metering, customers who can shift their profile to increase coincidence between their electricity consumption and PV generation would receive greater bill savings from PV than customers who do not, as excess generation is compensated at a different, lower rate than the full retail rate. The increase in bill savings depends on the customer's ability to shift their load profile.

Our analysis examining the bill savings from PV with IBP under the reference scenario $(I)$ highlights the significance of this rate structure for the customer economics of behind-the-meter PV. In particular, the variations in the value of bill savings across customers when PV is net metered with an IBP rate are even more significant than the variations associated with other rate options, compensation mechanisms, and electricity market scenarios. Under IBP, the value of bill savings is highly dependent on the customer's monthly use: customers with high levels of

\footnotetext{
${ }^{13}$ This is true as long as the customer's annual load is greater than or equal to their annual PV generation. If the customer's PV generation is greater than their annual load, the resulting bill credit carries over indefinitely or the PV customer is compensated for the annual excess generation at an avoided-cost rate (which is lower than the retail rate in most cases). In both cases the bill savings per $\mathrm{kWh}$ generated is lower, and hence customers often avoid sizing their PV systems to generate more than their average annual bill.
} 


\section{Conclusions}

Utilities throughout the United States are considering various rate structures that could affect the bill savings from residential PV substantially. To illuminate the customer economics behind such choices, this article examines the effects of three sets of assumptions related to wholesale electricity market design and retail rate structure, which are either currently implemented or have been considered by U.S. utilities or public utility commissions: (a) retail rates based on a wholesale market design with a price cap and capacity-cost recovery through a time-invariant volumetric charge, (b) rates with a two-part tariff and fixed-charge recovery through a fixed customer charge, and (c) a flat rate with IBP. Although the results presented here use data and 
assumptions based on California's electricity markets, the higher-level trends and conclusions might be applicable to various electricity market conditions, given the similar underlying dynamics between rate structures and customer economics of behind-the-meter PV. More specifically, we find that the erosion in bill savings associated with the combination of higher PV penetrations and time-varying rates (a finding in our previous article [1]) could be less severe with wholesale electricity market designs with a price cap when capacity costs are recovered via a fixed volumetric adder over all hours. The reduction in bill savings would potentially be exacerbated, however, by setting retail rates that include a fixed customer charge. Rates with IBP lead to large differences in bill savings from PV among customers, as the savings are dependent on the consumption levels. Larger customers, who face higher marginal rates for electricity, displace this higher priced electricity with PV generation, which leads to higher bill savings per kilowatt-hour of PV generation. Introducing IBP rates and/or revising existing IBP rates could have a substantial impact on customer economics of net-metered residential PV, potentially even more than from any of the other changes to electricity markets and rate design considered in this article series. Specifically, revising IBP rates to decrease the top tier rates would decrease bill savings for larger electricity customers. However, decreasing top tier rates may be accompanied by an increase in bottom tier rates, which would improve the bills savings from PV from smaller electricity customers.

Our results clearly indicate that, in addition to PV cost trajectories in the coming years, the future bill savings from customer-sited PV will be very sensitive to policies relating to retail electricity rate structures, PV compensation mechanisms, and wholesale electricity market design. These findings complement previous studies, which have either mainly focused on existing renewable deployment levels $[6,7,9]$ or the value of solar PV generation in the wholesale 


\section{Future Research}

The impact of value-preserving strategies on residential PV bill savings is a potential area for future research. Additional future research could expand on the scope of this study. For example, because this study relies on California-based assumptions, analyses based on assumptions in different regions would further corroborate this study's findings. Investigation of other rate design options, such as demand charges for residential customers, could augment results presented here. A study of commercial PV bill savings under various electricity market 
scenarios also would be useful, since load profiles and electricity rate structures vary between commercial and residential PV customers (e.g. understanding how demand charges impact the customer economics of PV with increasing renewable penetrations). Finally, insights could be gained through analyzing additional wholesale market scenarios and/or additional compensation mechanisms, such as "value of solar" rates that compensate PV generation at a price recalculated annually to reflect the value of solar generation to the utility.

\section{Acknowledgments}

This work was supported by the Office of Energy Efficiency and Renewable Energy (Solar Energy Technologies Program) and the Office of Electricity Delivery and Energy Reliability (National Electricity Delivery Division) of the U.S. Department of Energy under Contract No. DE-AC02-05CH11231. The authors would like to thank the anonymous reviewers, and Jarett Zuboy for his editorial support.

\section{References}

[1] Darghouth NR, Barbose G, Wiser RH. Customer-economics of residential photovoltaic systems (part 1): The impact of high renewable energy penetrations on electricity bill savings with net metering. Energy Policy 2014;67:290-300.

[2] Sáenz de Miera G, del Río González P, Vizcaíno I. Analysing the impact of renewable electricity support schemes on power prices: The case of wind electricity in Spain. Energy Policy 2008;36:3345-59.

[3] Sensfuß F, Ragwitz M, Genoese M. The merit-order effect: A detailed analysis of the price effect of renewable electricity generation on spot market prices in Germany. Energy Policy 2008;36:3086-94.

[4] Lamont AD. Assessing the long-term system value of intermittent electric generation technologies. Energy Econ 2008;30:1208-31.

[5] Mills AD, Wiser RH. Changes in the Economic Value of Photovoltaic Generation at High Penetration Levels: A Pilot Case Study of California. IEEE J Photovolt 2013;3:1394-402. 
[6] Darghouth NR, Barbose G, Wiser R. The impact of rate design and net metering on the bill savings from distributed PV for residential customers in California. Energy Policy 2011;39:5243-53.

[7] Borenstein S. Electricity Rate Structures and the Economics of Solar PV: Could Mandatory Time-of-Use Rates Undermine California's Solar Photovoltaic Subsidies? Cent Study Energy Mark Work Pap 2007;172:1-19.

[8] Borenstein S. The Market Value and Cost of Solar Photovoltaic Electricity Production. 2008.

[9] Mills A, Wiser R, Barbose G, Golove W. The impact of retail rate structures on the economics of commercial photovoltaic systems in California. Energy Policy 2008;36:326677.

[10] Darghouth NR, Barbose G, Wiser R. Net Metering and Market Feedback Loops: Exploring the Impact of Retail Rate Design on Distributed PV Deployment. Berkeley, CA: Lawrence Berkeley National Laboratory; 2015.

[11] Darghouth NR. Uncertainties in the Value of Bill Savings from Behind-the-Meter, Residential Photovoltaic Systems: The Roles of Electricity Market Conditions, Retail Rate Design, and Net Metering. Dissertation. University of California, Berkeley, 2013.

[12] US EIA. Annual Energy Outlook 2012 with Projections to 2035. Washington, DC, USA: U.S. Energy Information Administration, Office of Energy Analysis; 2012.

[13] CPUC. CPUC LTPP Technical Attachment Spreadsheet. San Francisco, CA, USA: California Public Utilities Commission; 2010.

[14] Darghouth NR, Barbose G, Wiser R. Electricity Bill Savings from Residential Photovoltaic Systems: Sensitivities to Changes in Future Electricity Market Conditions. Berkeley, CA: Lawrence Berkeley National Laboratory; 2013.

[15] US EIA. Annual Electric Power Industry Report. Washington, DC, USA: U.S. Energy Information Administration; 2012.

[16] DeBenedictis A. Personal Communication. Energy and Environmental Economics; 2010.

[17] Stoft S. Power System Economics: Designing Markets for Electricity. 1st ed. Wiley-IEEE Press; 2002.

[18] CPUC. Capacity Markets White Paper. San Francisco, CA, USA: Energy Division, California Public Utilities Commission.; 2004.

[19] Wen FS, Wu FF, Ni YX. Generation capacity adequacy in the competitive electricity market environment. Int J Electr Power Energy Syst 2004;26:365-72.

[20] Oren SS. Ensuring generation adequacy in competitive electricity markets. In: Griffin JM, Puller SL, editors. Electr. Deregul. Choices Chall., Chicago, IL: University of Chicago Press; 2005, p. 388-414.

[21] Joskow PL. Capacity payments in imperfect electricity markets: Need and design. Util Policy 2008;16:159-70. 
[22] Newell S, Spees K, Pfeifenberger J, Mudge R, DeLucia M, Carlton R. ERCOT Investment Incentives and Resource Adequacy. The Brattle Group, prepared for the Electric Reliability Council of Texas; 2012.

[23] Ontario Energy Board. Regulated Price Plan: Manual. 2009.

[24] Rábago KR, Libby L, Harvey T. Designing Austin Energy's Solar Tariff Using a Distributed PV Value Calculator, Denver, CO, USA: 2012. 
Table 1: Electricity market scenarios

\begin{tabular}{|c|c|c|c|c|c|}
\cline { 2 - 6 } \multicolumn{1}{c|}{} & \multicolumn{4}{c|}{2030 Renewable Penetration (energy) } & Distributed PV \\
\hline Scenario & PV & Wind & CSP w/storage & Other RE & $\begin{array}{c}\text { As proportion } \\
\text { of total PV }\end{array}$ \\
\hline Reference & $0.3 \%$ & $4.0 \%$ & $0.0 \%$ & $7.4 \%$ & $50 \%$ \\
\hline $33 \%$ RE Mix & $8.1 \%$ & $11.5 \%$ & $3.5 \%$ & $10.0 \%$ & $30 \%$ \\
\hline
\end{tabular}

Table 2: Assumptions for tiered flat rate - scenario I

\begin{tabular}{|c|c|c|c|c|}
\hline $\boldsymbol{t}_{\text {baseline }}$ & $\boldsymbol{t}_{\mathbf{2}}$ & $\boldsymbol{t}_{\mathbf{3}}$ & $\boldsymbol{s}_{\mathbf{2}}$ & $\boldsymbol{s}_{\mathbf{3}}$ \\
\hline 0.55 & $0.50 \cdot t_{\text {baseline }}$ & $1-t_{\text {baseline }}-t_{2}$ & $50 \%$ & $100 \%$ \\
\hline
\end{tabular}

Table 3: Tiered flat rate for reference scenario $(\$ / \mathrm{kWh})$

\begin{tabular}{|c|c|c|c|}
\hline & Tier 1 & Tier 2 & Tier 3 \\
\hline $\boldsymbol{R}_{\text {total }}$ & 0.120 & 0.180 & 0.360 \\
\hline
\end{tabular}


Table 4: Summary of all retail rates modeled

\begin{tabular}{|c|c|c|c|c|c|c|c|c|c|c|c|}
\hline \multirow[b]{2}{*}{$\begin{array}{l}\text { Scenario } \\
\text { number }\end{array}$} & \multirow[b]{2}{*}{$\begin{array}{c}\text { Wholesale } \\
\text { market } \\
\text { type }\end{array}$} & \multirow[b]{2}{*}{$\begin{array}{c}\text { Market } \\
\text { model }\end{array}$} & \multirow[b]{2}{*}{$\begin{array}{c}\text { Customer } \\
\text { charge? }\end{array}$} & \multirow[b]{2}{*}{$\begin{array}{l}\text { flat rate } \\
\text { (\$/kWh) }\end{array}$} & \multicolumn{3}{|c|}{$\begin{array}{c}\text { time of use rate } \\
\text { (peak season) }\end{array}$} & \multicolumn{3}{|c|}{$\begin{array}{l}\text { time of use rate } \\
\text { (off-peak season) }\end{array}$} & \multirow[b]{2}{*}{$\begin{array}{c}\text { Customer } \\
\text { charge } \\
\text { (\$/month }\end{array}$} \\
\hline & & & & & $\begin{array}{c}\text { low } \\
(\$ / k W h)\end{array}$ & $\begin{array}{c}\text { mid } \\
(\$ / k W h)\end{array}$ & $\begin{array}{l}\text { on-peak } \\
\text { (\$/kWh) }\end{array}$ & $\begin{array}{c}\text { low } \\
(\$ / k W h)\end{array}$ & $\underset{(\$ / k W h)}{\operatorname{mid}}$ & $\begin{array}{l}\text { on-peak } \\
\text { (\$/kWh) }\end{array}$ & \\
\hline$A$ & reference & $\begin{array}{l}\text { energy- } \\
\text { only }\end{array}$ & no & $\$ 0.179$ & $\$ 0.145$ & $\$ 0.164$ & $\$ 0.493$ & $\$ 0.142$ & $\$ 0.150$ & - & - \\
\hline B & reference & $\begin{array}{l}\text { price } \\
\text { cap }\end{array}$ & no & $\$ 0.179$ & $\$ 0.165$ & $\$ 0.184$ & $\$ 0.274$ & $\$ 0.162$ & $\$ 0.170$ & - & - \\
\hline$C$ & $33 \%$ RE & $\begin{array}{l}\text { energy- } \\
\text { only }\end{array}$ & no & $\$ 0.192$ & $\$ 0.162$ & $\$ 0.186$ & $\$ 0.572$ & $\$ 0.159$ & $\$ 0.164$ & $\$ 0.167$ & - \\
\hline$D$ & $33 \%$ RE & $\begin{array}{l}\text { price } \\
\text { cap }\end{array}$ & no & $\$ 0.192$ & $\$ 0.181$ & $\$ 0.200$ & $\$ 0.280$ & $\$ 0.178$ & $\$ 0.183$ & $\$ 0.186$ & - \\
\hline$E$ & reference & $\begin{array}{l}\text { energy- } \\
\text { only }\end{array}$ & Yes & $\$ 0.078$ & $\$ 0.044$ & $\$ 0.063$ & $\$ 0.392$ & $\$ 0.041$ & $\$ 0.049$ & - & $\$ 59$ \\
\hline$F$ & $33 \%$ RE & $\begin{array}{l}\text { energy- } \\
\text { only }\end{array}$ & Yes & $\$ 0.087$ & $\$ 0.057$ & $\$ 0.081$ & $\$ 0.467$ & $\$ 0.054$ & $\$ 0.059$ & $\$ 0.062$ & $\$ 59$ \\
\hline$G$ & reference & $\begin{array}{l}\text { energy- } \\
\text { only }\end{array}$ & reduced & $\$ 0.148$ & $\$ 0.114$ & $\$ 0.133$ & $\$ 0.462$ & $\$ 0.111$ & $\$ 0.119$ & - & $\$ 20$ \\
\hline$H$ & $33 \%$ RE & $\begin{array}{l}\text { energy- } \\
\text { only }\end{array}$ & reduced & $\$ 0.157$ & $\$ 0.127$ & $\$ 0.151$ & $\$ 0.537$ & $\$ 0.124$ & $\$ 0.129$ & $\$ 0.132$ & $\$ 20$ \\
\hline 1 & reference & $\begin{array}{l}\text { energy- } \\
\text { only }\end{array}$ & No & $\begin{array}{c}\text { Tiered } \\
\text { (see } \\
\text { Table 3) }\end{array}$ & - & - & - & - & - & - & - \\
\hline
\end{tabular}

Table 5: Summary Results, bill savings for all scenarios and all rates considered

\begin{tabular}{|c|c|c|c|c|c|c|c|c|c|}
\hline \multirow[b]{3}{*}{$\begin{array}{l}\text { Scenario } \\
\text { number }\end{array}$} & \multirow[b]{3}{*}{$\begin{array}{c}\text { Wholesale market } \\
\text { type }\end{array}$} & \multirow[b]{3}{*}{$\begin{array}{c}\text { Market } \\
\text { model }\end{array}$} & \multirow[b]{3}{*}{$\begin{array}{l}\text { Customer } \\
\text { charge }\end{array}$} & \multicolumn{6}{|c|}{ Bill Savings from PV (\$/kWh) } \\
\hline & & & & \multicolumn{3}{|c|}{ net metering } & \multicolumn{3}{|c|}{$\begin{array}{c}\text { hourly netting } \\
\text { (75\% PV-to-load ratio) }\end{array}$} \\
\hline & & & & $\begin{array}{l}\text { flat } \\
\text { rate }\end{array}$ & $\begin{array}{l}\text { TOU } \\
\text { rate }\end{array}$ & $\begin{array}{l}\text { RTP } \\
\text { rate }\end{array}$ & $\begin{array}{l}\text { flat } \\
\text { rate }\end{array}$ & $\begin{array}{l}\text { TOU } \\
\text { rate }\end{array}$ & $\begin{array}{l}\text { RTP } \\
\text { rate }\end{array}$ \\
\hline$A$ & reference & $\begin{array}{c}\text { energy- } \\
\text { only }\end{array}$ & $\$ 0$ & 0.179 & 0.201 & 0.181 & 0.125 & 0.136 & 0.132 \\
\hline$B$ & reference & price cap & $\$ 0$ & 0.179 & 0.187 & 0.183 & 0.113 & 0.117 & 0.117 \\
\hline C & $33 \% \mathrm{RE}$ & $\begin{array}{l}\text { energy- } \\
\text { only }\end{array}$ & $\$ 0$ & 0.192 & 0.173 & 0.152 & 0.109 & 0.105 & 0.099 \\
\hline$D$ & $33 \% \mathrm{RE}$ & price cap & $\$ 0$ & 0.192 & 0.186 & 0.18 & 0.107 & 0.105 & 0.104 \\
\hline$E$ & reference & $\begin{array}{l}\text { energy- } \\
\text { only }\end{array}$ & $\$ 59$ & 0.075 & 0.097 & 0.096 & 0.08 & 0.092 & $\mathrm{n} / \mathrm{a}$ \\
\hline$F$ & $33 \% \mathrm{RE}$ & $\begin{array}{l}\text { energy- } \\
\text { only }\end{array}$ & $\$ 59$ & 0.084 & 0.064 & 0.058 & 0.064 & 0.058 & $\mathrm{n} / \mathrm{a}$ \\
\hline
\end{tabular}




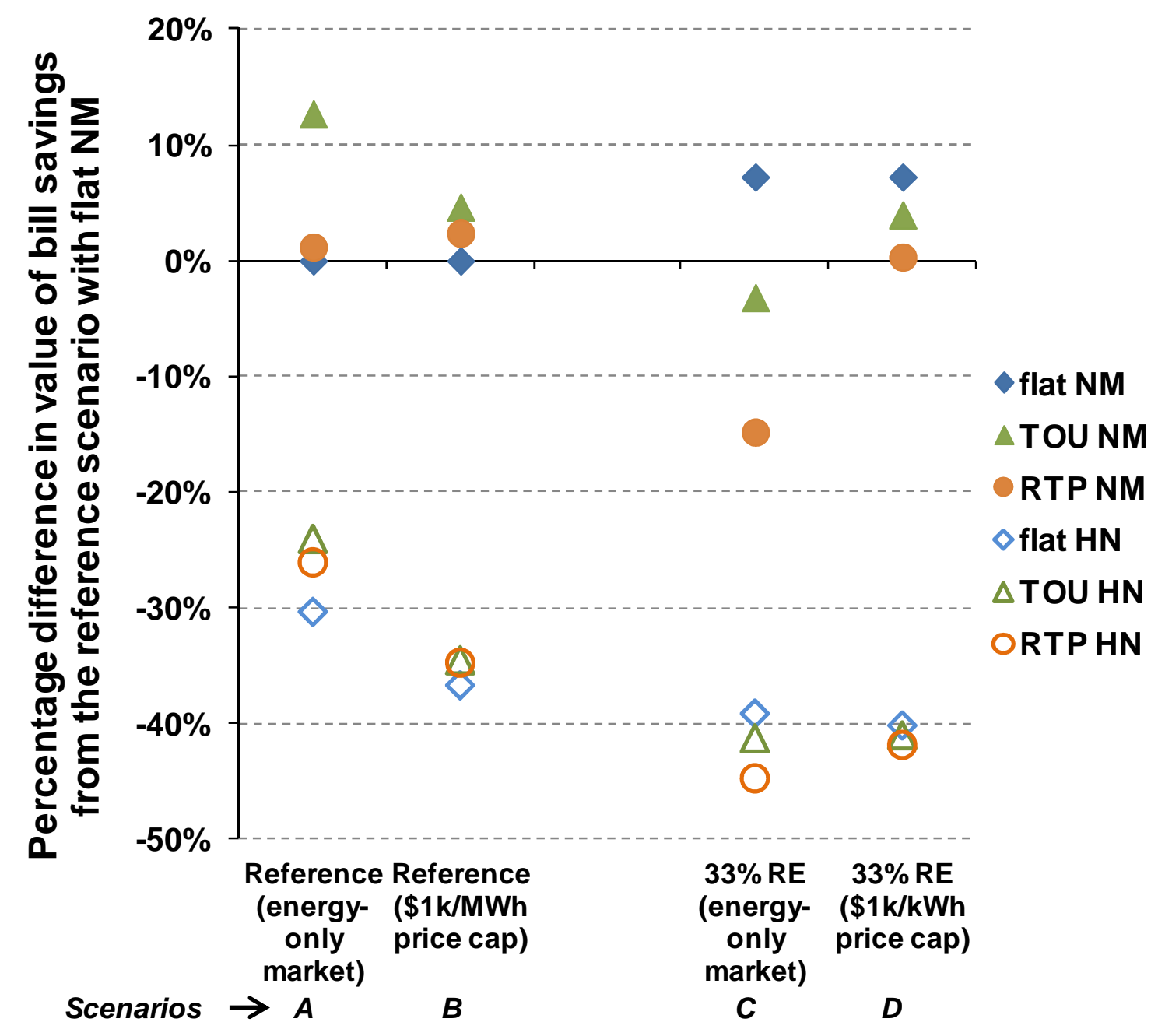

Figure 1: Value of bill savings for the reference scenario and the $33 \% \mathrm{RE}$ mix scenario, relative to the reference scenario's flat rate with net metering, assuming an energy-only market and a lower price cap with a capacity-cost adder (75\% PV-to-load ratio assumed) 


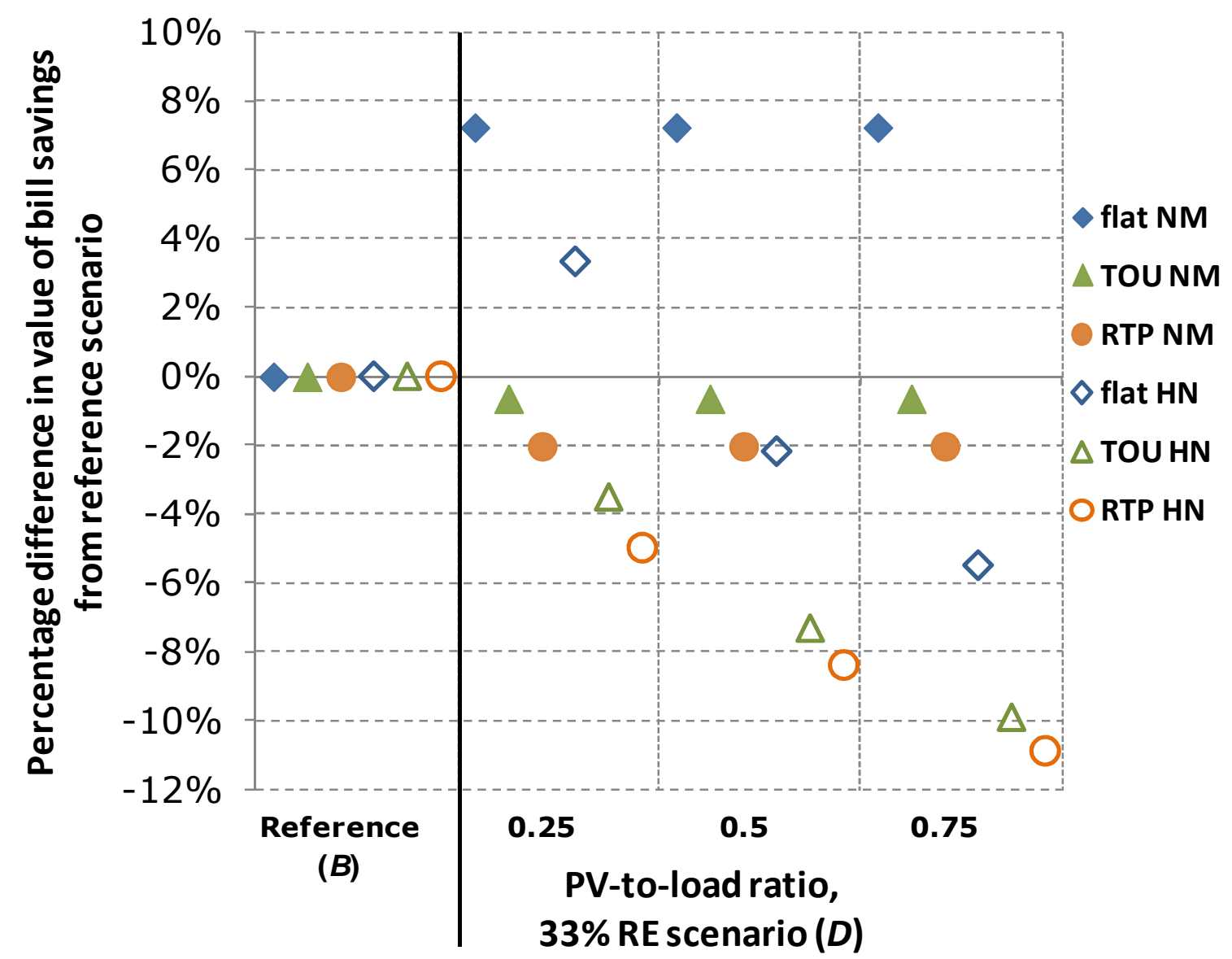

Figure 2. Comparing value of bill savings between reference and 33\% RE mix scenarios, assuming a lower wholesale price cap and a capacity-cost adder 
Figure 3. Bill savings for the reference scenario assuming a two-part tariff structure (with customer charge), relative to the reference scenario assuming only a volumetric charge Note: As explained in Section 2.2, the RTP rate with a two-part tariff structure is defined differently than the RTP rate with volumetric charges only and hence is not compared directly in this figure. 


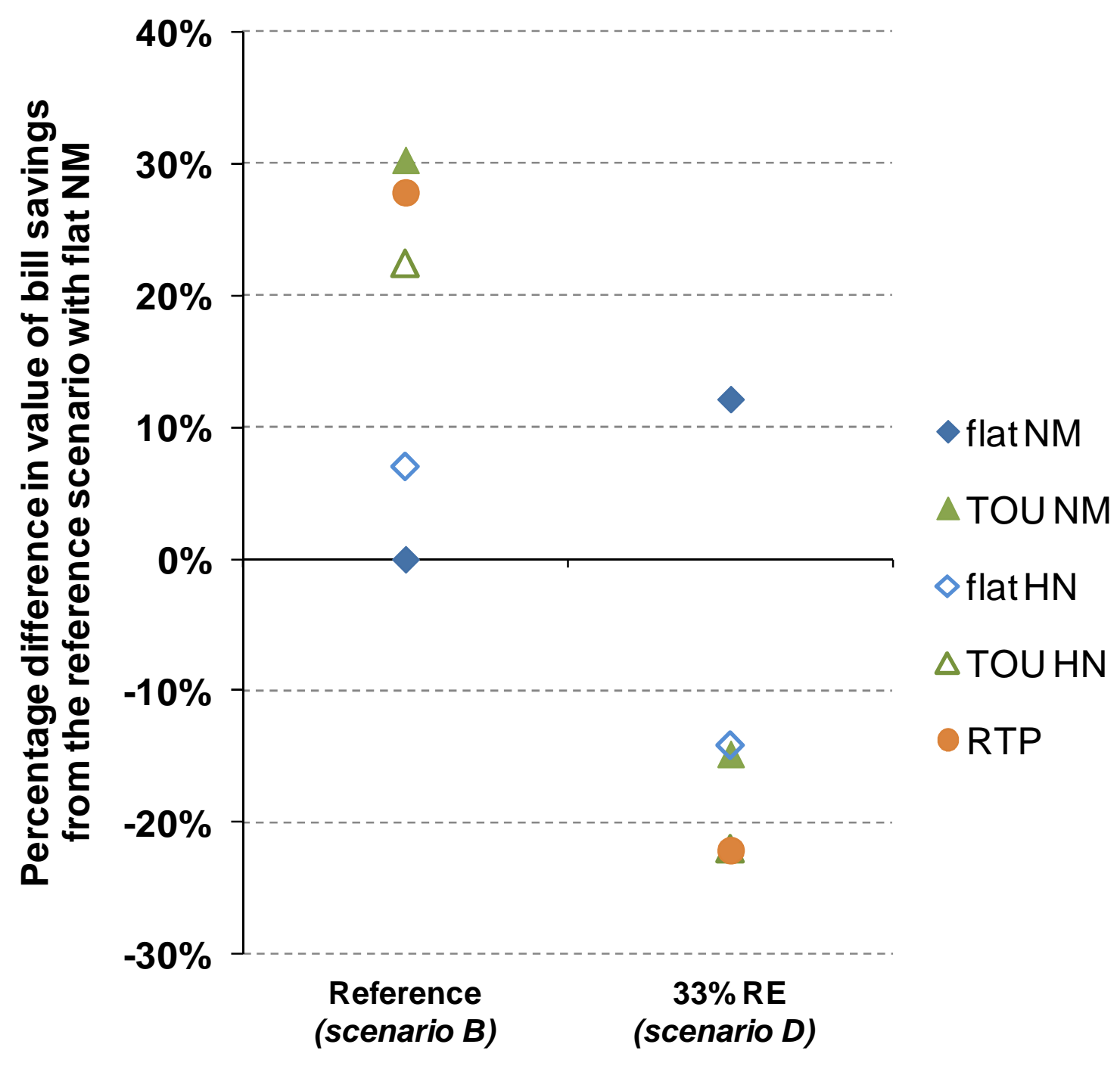

Figure 4. Value of bill savings for the reference scenario assuming a two-part tariff structure, relative to the flat rate with net metering 


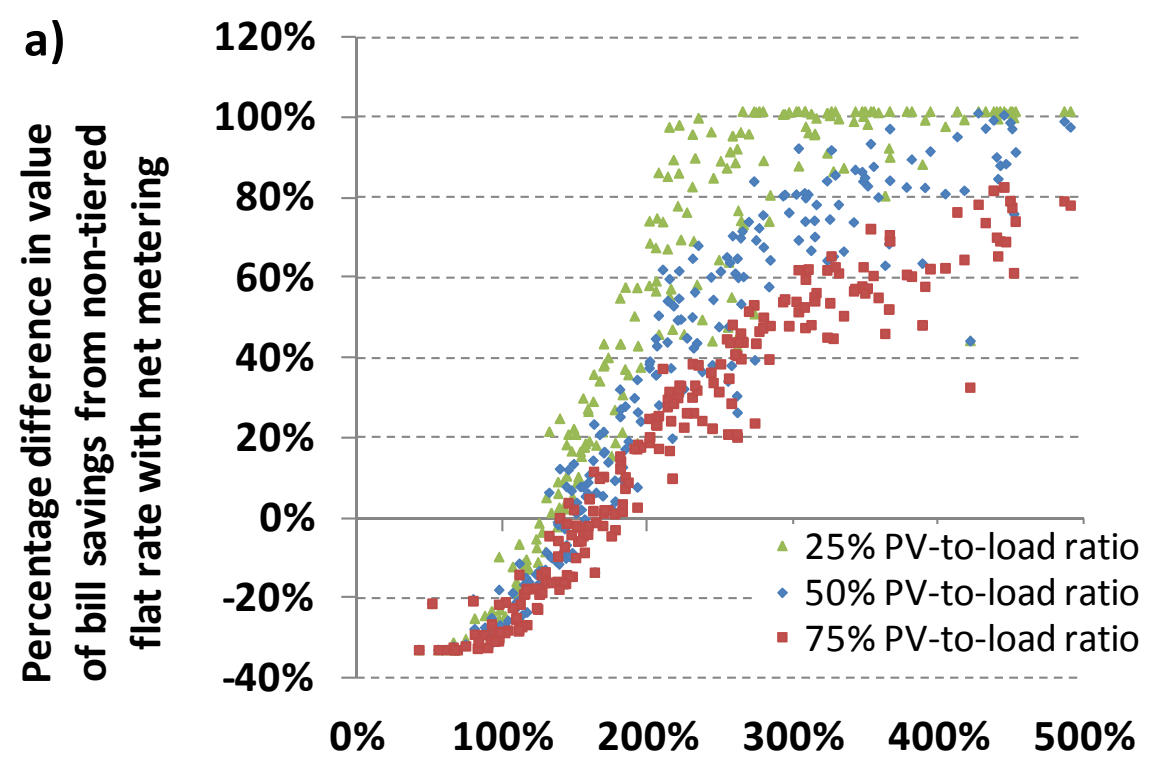

Mean Monthly Consumption (\% of baseline)

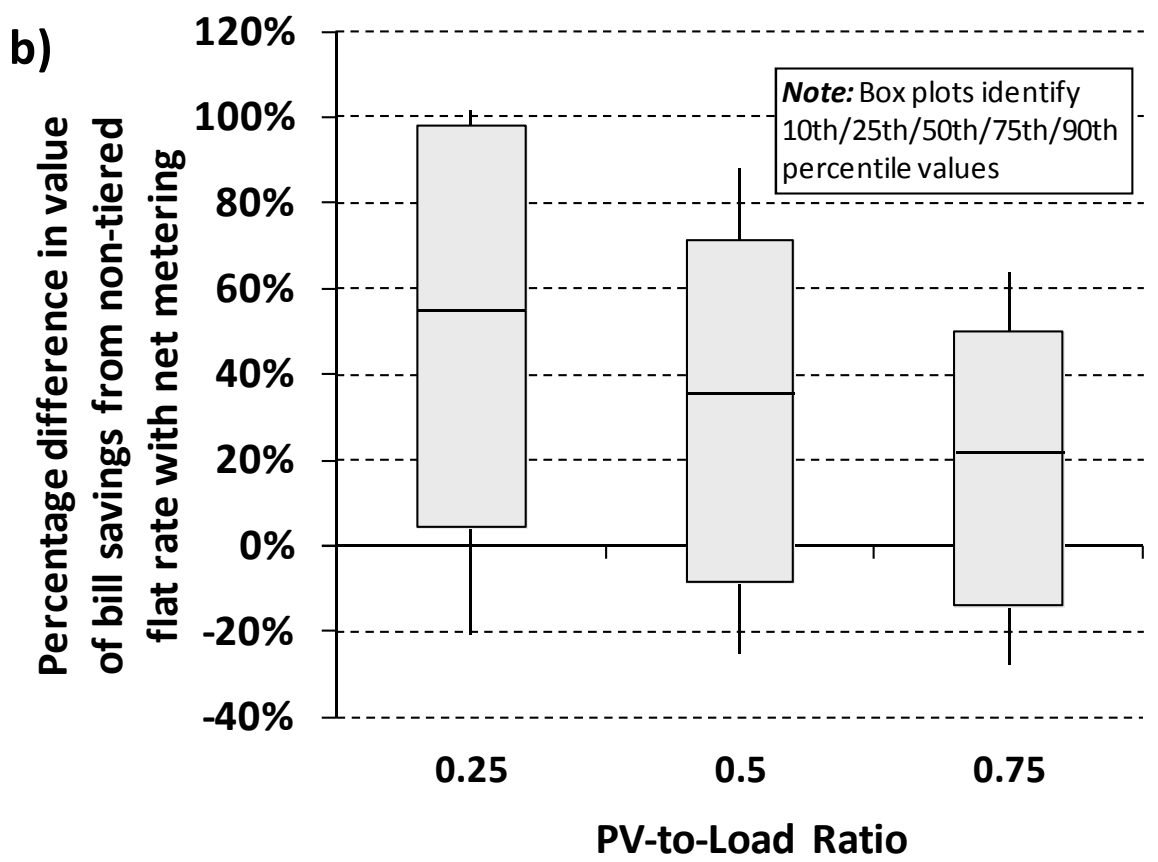

Figure 5: a) Value of bill savings for PV customers under the tiered flat rate as a function of customer gross electricity consumption, for three levels of PV-to-load ratio under the reference scenario $(I)$. b) Box-and-whiskers plot showing distribution in value of bill savings for PV customers under the tiered flat rate for three levels of PV-to-load ratio. All 
values are in percentage difference from the non-tiered flat rate with net metering from the reference scenario (hence the more positive the value on the y-axis, the higher the value of bill savings). 